Pedagogía y Saberes $n .^{\circ} 56$

Universidad Pedagógica Nacional

Facultad de Educación. 2002. pp. 13-26

\title{
Paulo Freire: de la Secretaría de Educación a las Escuelas Públicas
} Populares Latinoamericanas $(1989-2020)^{*}$

Paulo Freire: From the Secretary of Education to the Latin American Popular Public Schools (1989-2020) Paulo Freire: Da Secretaria de Educação às Escolas Públicas Populares da América Latina (1989-2020)

Roberto Elisalde * ricanas (1989-2020). Pedagogía y Saberes, (56). https://doi.org/10.17227/pys.num56-13085 


\section{Resumen}

En este trabajo de investigación nos proponemos reconstruir históricamente y problematizar la experiencia desarrollada por Paulo Freire como secretario de Educación en el Municipio de São Paulo en el período 1989-1991, durante la gestión de la Prefecta Luiza Erundina, perteneciente al Partido de los Trabajadores. Asimismo, se pretende analizar cómo desde esta experiencia renovadora de gestión freiriana se sientan las bases de nuevas estrategias que influenciaron de manera inédita en las acciones y reflexiones de los movimientos sociales latinoamericanos en el terreno de la educación pública y popular durante el nuevo milenio.

Palabras clave:

educación popular; Paulo Freire; Estado; movimientos sociales; escuelas

\section{Abstract}

In this work, we propose to problematize and reconstruct historically one of the least referenced paths in Paulo Freire's legacy. That is, the production and actions carried out in the years in which the legendary educator assumed the management of the Municipal Secretariat of Education of São Paulo during 1989-1991, during the government of the Party of the Workers. Likewise, we are going to analyze how from this renovating experience, the foundations of new conceptualizations and strategies are laid that will influence in an unprecedented way the actions and future reflections of Latin American social movements in the field of public and popular education during the new millennium.

\section{Keywords:}

popular education; Paulo Freire; state; social movements; schools

\section{Resumo}

Neste trabalho de pesquisa, nos propomos reconstruir historicamente e problematizar a experiência desenvolvida por Paulo Freire como Secretário Municipal de Educação de São Paulo no período 1989-1991, durante o governo da Prefeita Luiza Erundina do Partido dos Trabalhadores. Assim mesmo, pretende-se analisar como a partir dessa experiência renovadora de gestão freiriana, se lançam os alicerces de novas estratégias que influenciaram de maneira inédita nas ações e reflexões dos movimentos sociais latino-americanos no campo da educação pública e popular durante o novo milênio.

\section{Palavras-chave:}




\section{Introducción}

En esta investigación nos proponemos analizar la gestión de Paulo Freire a cargo de la Secretaría de Educación Municipal de São Paulo. Esta iniciativa de gestión aspiró a desarrollar un proyecto que fuera algo más que una administración de lo existente, según lo enunciaban los representantes del equipo de educación del Partido de los Trabajadores. Destacaban la necesidad de implementar un proyecto de construcción de poder popular, basado en las ideas centrales de la educación freirianas y desde una praxis avalada por la historia de militancia social del propio Freire y su equipo. En esta gestión, las relaciones entre el Estado y los movimientos sociales fueron centrales y se desplegaron con destreza y convicción, despojadas de políticas de cooptación, judicialización o represión. El Programa Mova de Alfabetización, las iniciativas de Planeamiento participativo fueron un claro ejemplo de ello. En esta misma línea, el conjunto de reformas de la etapa fueron presentadas y asumidas por las organizaciones sociales y la Secretaría de Educación como un proyecto de educación popular crítico de la hegemonía cultural tradicional y en favor de la construcción de una democracia radical.

Las fuentes relevadas en este trabajo están basadas en los archivos documentales pertenecientes a la gestión de Paulo Freire en la Secretaría Municipal de Educación de São Paulo durante 1989 y 1991, así como en materiales periodísticos (diarios paulistas, como Folha, Estado, entre otros) y revistas de educación del estado y el municipio en cuestión.

En lo que respecta a las publicaciones sobre la experiencia de Paulo Freire al frente de la Secretaría Municipal de Educación entendemos que no son realmente numerosas. Podemos mencionar el trabajo autorreflexivo del propio Freire, $A$ educação na cidade (2000), que es en realidad una compilación de Moacir Gadotti; otra investigación sobre la temática es el libro del portugués Licinio Lima, Organização democratização escolar e democracia radical. Paulo Freire e a governarão democrática da escola publica (2002). Este trabajo asume una perspectiva organizacional y administrativista, analizando la naturaleza institucional y democratizante de la gestión freiriana. Por otra parte, y desde un enfoque reivindicatorio de los valores democráticos de la experiencia, se destaca el libro de Torres, O'Caliz y Wong, Educação e democracia. Praxis de Paulo Freire en S. Paulo.

1 La documentación referenciada de la gestión de Freire se encuentra archivada en la Biblioteca del Instituto Paulo Freire, São Paulo, Brasil.
En los últimos años se publicaron otras producciones referidas a la gestión de Freire, pero sobre temas específicos, como por ejemplo los Consejos Populares o alguna política pública en particular, como fue el caso de los movimientos de alfabetización (Mova). Así lo expresa el libro de Ángela Antunes, Aceita um conselho? Como organizar o colegiado escolar, o la iniciativa del Mova (Moacir Gadotti, Mova Brasil). La mayoría de estas investigaciones están escritas desde una perspectiva autobiográfica o participativa ya que muchos de los autores formaron parte de la experiencia, sea como integrantes de la administración (como fue el caso del propio Gadotti) o desde las iniciativas llevadas adelante en las escuelas de San Pablo en las que se aplicaron las reformas freirianas, tal como ocurrió con la producción de Ángela Antúnez. Recientemente también se escribieron tesis de maestría o doctorado que abordaron temáticas sobre algún aspecto de la gestión, como el rol de los directores de escuela, los consejos escolares o los planes de la gestión.

\section{Paulo Freire en la gestión educativa de São Paulo (1989-1991)}

Cuando en 1989 el Partido de los Trabajadores triunfó sorpresivamente en la elección municipal de São Paulo, tuvo que organizar con premura la nueva gestión de gobierno. En ese escenario la cartera de educación tenía un candidato y equipo de trabajo asegurado en la figura de Paulo Freire. Por esos años, el educador brasileño ya era considerado un símbolo regional de la educación popular y de resistencia contra las dictaduras latinoamericanas ${ }^{2}$.

En este marco, por primera vez, a diferencia de otras situaciones históricas, la educación popular se entremezclaba en el campo de la política pública

2 En 1988 Luiza Erundina fue elegida como prefecta del municipio de San Pablo. Pertenecía a una de las corrientes más comprometidas con la construcción de una democracia de masas y con el desafío de acompañar "la construcción del socialismo en Brasil", según afirmaba. Su condición de mujer y militante la distanciaban de un clásico funcionario/a de Estado. Estas posturas le valieron cierta indiferencia de los sectores más electoralistas y moderados de su propio partido. Paulo Freire, identificado y alineado claramente con Erundina, sufrirá también en su gestión educativa los embates de los sectores más institucionalistas del Partido de los Trabajadores, así como las críticas de la derecha partidaria y mediática (los principales diarios serán sus principales cuestionadores) del estado de São Paulo. Hacia 1990 la gestión municipal recibirá una mayor presión y cuestionamiento partidario, obligándola a tomar otro cariz en su gestión. Este corrimiento hacia la moderación coincidirá con la renuncia de Paulo Freire a la Secretaría de Educación “por razones personales” en 1991. 
de una manera sistemática y contundente. Paulo Freire y su equipo de trabajo entendían que era el momento de sumar fuerzas desde el Estado, como parte de la estrategia definida desde el Partido de los Trabajadores. Consideraban que se trataba de acompañar un proyecto político de base y con aspiraciones contrahegemónicas. Esta decisión trajo controversias dentro del equipo freiriano. Muchos de ellos consideraban que esta decisión era como comenzar de nuevo, e incluso más grave, Porque ese mismo Estado había sido el responsable -en años anteriores- de la expulsión masiva de las aulas de jóvenes y adultos, e incluso había actuado con políticas represivas hacia docentes y educadores populares.

Tal como lo señalamos en otros trabajos, la exclusión de la educación formal se presentó como una de las diferentes dimensiones de la desigualdad propia del capitalismo de los años 80 y 90 . La acreditación de la escuela primaria y secundaria se estaba constituyendo en una de las problemáticas más preocupantes del periodo. Luego de la oleada neoliberal, esta situación era una condición tristemente masiva y arraigada en las nuevas camadas de niños/as y jóvenes latinoamericanos/as. La educación popular debía complejizar sus ejes de construcción, pasar hacia dentro de las fronteras del Estado para organizar, reclamar y luchar por políticas públicas que resolvieran las necesidades de los(as) trabajadores(as), respetaran la autonomía/autogestión de los movimientos sociales y plantearan la construcción de una educación como herramienta emancipadora, solidaria y promotora de la organización popular³.

En aquellos años emergió en Brasil el Partido de los Trabajadores, que, con un fuerte arraigo popular en las masas obreras y campesinas, comenzaba a obtener resultados positivos en los actos electorales que se iban desarrollando de manera gradual y controlada por la herencia institucional de la dictadura de 1964. Al mismo tiempo, sus militantes y dirigentes partidarios se comprometían públicamente en la construcción de una propuesta política que asumiera la difícil tarea de redimir la "lógica incorregible del capital" ${ }^{4}$, pero dentro de las esferas del Estado. Los debates fueron intensos y los escenarios políticos en

3 Estos planteos fueron ciertamente habituales en los documentos freirianos de educación popular desde fines de los años 80. Sobre la situación socioeducativa del Brasil, véase Gadotti (2008). Un mayor desarrollo de la situación brasileña de este periodo y el punto de vista del equipo de Paulo Freire al respecto puede verse en Elisalde (2020).

4 Estas expresiones pertenecen a Mészáros (2003). cada estado regional fueron de diferente naturaleza ${ }^{5}$. En el campo educativo, la gestión de Paulo Freire al frente de la Secretaría y del Partido de los Trabajadores daría cuenta de nuevas formas de la política pública, combinada en esta oportunidad con las tradiciones de la educación popular.

Las bases y principios de la flamante gestión se basaban en los aportes de los clásicos, sobre todo de tradición gramsciana, y en destacadas referencias de la educación popular brasilera. Educadoras/ es como Marilena Cauí, Florestan Fernandes, Luiz Wanderley y el mismo Paulo Freire entendían a la educación pública como una cuestión de poder, tomando distancia de las concepciones liberales que concebían que la masividad de la escuela bastaba para interpretar y concebir su carácter popular.

Esta corriente de educadores populares pensaba que la escuela pública debía ser "escuela única", sin opciones privatistas y sin las aspiraciones homogeneizantes del Estado liberal. Creían en una escuela "hecha por el pueblo y no solo para el pueblo", como decía Florestan Fernandes (1983).

Moacir Gadotti, nombrado jefe de gabinete de Freire en 1989, afirmaba que el Estado era un campo de lucha y que las conflictividades que se desarrollaran durante la nueva etapa tendrían que tener como resultado políticas educativas favorables a los intereses de los y las trabajadoras. Asimismo, desde el equipo de Freire identificaban la existencia de contradicciones en la "escuela tradicional", motivo por el cual esta institución debía ser agente en la lucha de clases y afirmaban, por lo tanto, que "podía ser popular y transformadora en el interior del propio Estado burgués":

Una escuela en la que el educador sepa asociar la lucha por la socialización de saber con la lucha principal de la clase trabajadora, que es la lucha por el fin de la dominación política y de la explotación económica de la burguesía sobre los trabajadores.

(Gadotti, 2003, p. 54)

Por ello, la cuestión de la hegemonía de la clase trabajadora debía pasar por la preparación de las masas a través de los consejos de trabajadores, por la autogestión organizativa y la autonomía política. Según estas consideraciones se trataba de reivindicar la acción frente a la pasividad de las llamadas "teorías reproductivistas" y tomar distancia del falso neutralismo de la tradición liberal.

5 Es importante aclarar que al asumir Luiza Erundina la gestión en São Paulo, dentro del Partido de los Trabajadores se generó un profundo debate acerca de los límites y posibilidades que el Partido tendría para asumir posiciones radicalizadas, tal como lo señalaban sus principios programáticos. Véase Keck (1991). 
Un aspecto que el propio Gadotti se encargó de recuperar algún tiempo después de transcurrida esta experiencia de gestión, se refería a la relación y construcción de poder popular dentro de la política pública y, por ende, del Estado. Su postura efectiva estaba argumentada en aquel entonces en el respaldo de un partido de izquierda en ascenso a nivel estadual y nacional, como lo era el Partido de los Trabajadores.

La educación popular [...] tiene a su favor el surgimiento de las nuevas fuerzas del poder local democrático (Municipio de San Pablo) y también la presencia en los aparatos burocráticos estatales de antiguos militantes o simpatizantes del movimiento de educación popular. Pero tiene sobre todo una nueva arma teórica, que nació en la práctica de la organización popular, para enfrentar a los nuevos desafíos de este final de siglo. La lucha contra el analfabetismo [y la exclusión] tiene la marca de las organizaciones y movimientos populares. El acompañamiento y el diálogo con el estado es esencial si se quiere enfrentar con éxito ese desafío, que es [...] nacional e internacional. (Gadotti, 2003, p. 123; énfasis del original)

También reflexionó junto a Freire sobre la naturaleza de la relación del Estado con los movimientos sociales. En este punto subrayaba la necesidad de que el movimiento social fuera parte integral de este proceso transformador, pero afirmaba que más allá de su identificación política o no con la gestión de gobierno debía mantener su capacidad autogestionadora en lo organizativo y su autonomía en lo político.

\section{El desafío de construir poder popular en las esferas del Estado}

La asunción de Freire a cargo de la Secretaría de Educación ${ }^{6}$ fue interpretada como un gran desafío, principalmente para los principios y valores de la educación popular ${ }^{7}$. Recordemos que las principales ideas de Pedagogía del oprimido y Concientización - rechazo a la educación bancaria, la reivindicación de la dialoguicidad, la formación de sujetos políticos y sus referencias en esos años a la construcción de

6 Paulo Freire fue uno de los cofundadores del Partido de los Trabajadores en los años 80. Por lo tanto, debe considerarse como un militante más que como una figura "extrapartidaria".

7 Freire ya había ejercido cargos de gestión antes de 1989. Lo hizo en la Direção de Departamento de Extensão de la Universidad de Recife en 1962; en 1963 fue miembro del Conselho Estadual de Educação de Pernambuco, luego en la presidencia de la Comisión Nacional de Cultura Popular y en la coordinación en el Plan Nacional de Alfabetização de Adultos en 1964. poder popular a través de las escuelas- habían sido formulados en tiempos en los que el campo de la teoría y praxis de la educación popular era la alfabetización de jóvenes y adultos en territorios no institucionales, a lo sumo desde programas estatales; ahora, el desafío era diferente, se trataba de "recrear y aplicar" aquellos principios, como decía Freire, al escenario del sistema escolar público.

Ya en la Secretaría de educación, Paulo Freire se presentó en su doble condición de intelectual y militante comprometido con las causas populares, más que un funcionario de estado convencional. En esta dirección se orientaron sus primeras intervenciones y documentos de gestión, es decir, establecer como prioritario la construcción de una escuela que sintetizara aquellos elementos que fueron consideradas conquistas colectivas de las instituciones tradicionales (masividad, laicidad, gratuidad, entre otras), junto a los principios emancipadores de una educación radicalizada.

En uno de los documentos publicados por la Secretaría de Educación de São Paulo, "Construyendo la Educación Pública Popular" fueron presentados los análisis y diagnósticos iniciales del panorama educativo de la Municipalidad de São Paulo: predominando las dificultades y retrasos en los problemas de infraestructura escolar, la precarización de la labor docente y la escasez de vacantes en las escuelas, entre muchas otras problemáticas.

Un diagnóstico realizado durante el mes de diciembre nos mostró que la situación física de nuestras 703 escuelas municipales es preocupante: faltan más de 30.000 conjuntos de sillas para los alumnos y mesas para los profesores; $40 \%$ de los profesores están ejerciendo sus funciones precariamente en comisión; muchos niños y jóvenes adultos quedan afuera de las escuelas por la falta de vacantes; la población va buscado formas para resolver estas deficiencias y creado alternativas diversificadas de educación que no son consideradas por el sistema. (SEM-SP, 1989, p. 20)

A partir de esta situación, las metas centrales que definieron la política de gobierno de la Secretaría de Educación fue recuperar la presencialidad de los niños y niñas de las clases populares que estaban fuera del sistema educativo; llevar adelante estrategias de planificación participativa y autogestión con la idea de comprometer a la comunidad en los asuntos públicos, eliminar el analfabetismo y mejorar la calidad educativa, basada en la formación y el compromiso colectivo. Los documentos destacaban que el modelo pedagógico político que se impulsaba era el de las escuelas públicas 
populares. En un documento central dado a conocer a poco de haber asumido, Freire y su equipo afirmaban al respecto a la calidad educativa:

La calidad de la escuela deberá ser medida no solo por la cantidad de contenidos transmitidos y asimilados, sino igualmente por la solidaridad de clase que haya construido, por la posibilidad que todos los usuarios de la escuela -incluidos padres y comunidad - tuvieron de utilizarla como un espacio para la elaboración de su cultura. (SME-SP, 89, p. 67)

La lucha por la escuela pública y popular se tradujo también en la necesidad de aceptar el vínculo de la gestión con las organizaciones sociales y las escuelas. Se trataba de conformar una red de articulaciones con nuevos entramados institucionales y de participación. La Secretaría de educación deseaba que su dinámica no fuera solamente elaborar disposiciones y normativas "desde arriba", sino, por el contrario, procurar la apropiación creativa de la escuela por la misma comunidad para transformarla, como decía Freire, en "un espacio de organización política de las clases populares" y de "formación de sujetos sociales" (SME-SP, 1990, p. 45).

Desde los aportes de Paul Singer ${ }^{8}$, la gestión del Partido de los Trabajadores asumió como centrales la participación popular en las políticas de organización económica, especialmente a través de creación y aplicación de los llamados presupuestos participativos en todos aquellos distritos donde gobernaran. Democratización, planeamiento y descentralización/autogestión fueron algunas de las nuevas ideas que el Partido llevó a cabo en sus gestiones de gobierno:

Una concepción de planeamiento donde las políticas de acción del poder público se dan de arriba para abajo, de forma centralizada, no puede servir a un gobierno que tiene como preocupación la gestión del poder público en un contexto de democracia participativa. Un gobierno en busca de la participación popular como compañera en la gestión de la cosa pública precisa tener en claro que el servicio público se construyó en las diferentes instancias. (SME-SP, 1990, p. 23)

Desde estas concepciones fue presentado el llamado "Proyecto pedagógico emancipador" con la idea de iniciar una profunda reforma curricular. Freire

8 Paul Singer fue uno de los principales referentes del Partido de los Trabajadores respecto a políticas de gestión y administración popular y participativa. pensaba que la disciplina de trabajo, el estudio comprometido, la solidaridad de clase y la cooperación no debían ir separados; al contrario, entendía que unidos expresaban los principios y valores colectivos que el pueblo trabajador debía asumir en sus procesos de formación educativa.

En uno de los documentos de la Secretaría señalaba: "Aprender é gostoso, mas exige esforço", así como luego en el libro Pedagogía de la autonomía, de Freire, ya estaban presentes estas ideas que respondían y cuestionaban aquellas interpretaciones que asociaban las nociones de la educación popular freiriana con las concepciones "poco rigurosas" o desentendidas de cualquier aspiración comprometida con el estudio. En aquella publicación se destacaba una vigorosa apelación a la cultura del trabajo educativo, al serio compromiso por la investigación y el estudio, promoviendo la libertad y la autonomía del ser (Freire, 1998).

La seguridad con que la autoridad docente se mueve implica que el docente se base en una competencia profesional [...] El profesor que no tome en serio su formación, que no estudie, que no se esfuerce para estar a la altura de su tarea, no tiene fuerza moral para coordinar las actividades de su clase [...] El clima de respeto que nace de las relaciones justas, serias, humildes, generosas en que la autoridad docente y la libertad de los alumnos asumen éticamente [...] el carácter formador del espacio pedagógico. (Freire, 1998, pp. 55-56)

Asimismo, Freire solía señalar la politicidad del acontecimiento educativo y afirmaba que el pueblo no debía participar de la escuela para aceptar pasivamente instrucciones, recetas, represiones o sanciones, sino para ser parte de la construcción colectiva del saber. Por ello debía recibir tanto los aportes de los maestros y profesores como de los estudiantes, y convertir sus prácticas en un instrumento de lucha que les permita transformarse en sujetos de su propia historia:

No debemos llamar a nuestro pueblo a la escuela para recibir postulados, instrucciones, recetas, amenazas o puniciones, sino para participar colectivamente de la construcción de un saber [...] que se torne instrumento de lucha [...] La participación popular en la creación de la cultura y la educación rompe con la tradición de que sólo la élite es competente y sabe cuáles son las necesidades e intereses de toda la sociedad. (SME-SP, 1989. p. 35; énfasis del original). 


\section{Escuelas públicas y reformas freirianas 9}

La naturaleza de la escuela pública estatal brasileña era analizada con fuertes críticas por el equipo de Freire; pensaban que era necesario hacer popular lo público y que las prácticas burocráticas se habían apropiado del sistema escolar estatal. También argumentaban que un sincero y transparente diagnóstico debía ser el mejor comienzo para transformar la escuela:

La escuela brasilera no es necesariamente pública. Por el contrario, es en el sistema de enseñanza que encontramos con mayor profundidad, por el carácter clientelístico de la burocracia escolar, una enraizada mentalidad privatista de la cosa pública. La estructura administrativa de la escuela, determinada y articulada en gran parte a partir de las orientaciones del director, que de ella toma "posesión", la obtención del consenso por el servilismo o por el cambio de favores, la nominación de cargos de confianza en las instancias intermedias o superiores apoyadas en relaciones atravesadas por el clientelismo político, la falta de autonomía para la elaboración y ejecución de proyectos pedagógicos en el ámbito de la unidad escolar. (Sposito, 1984, p. 34)

Las políticas descentralizadoras fueron parte de las estrategias que la gestión asumió como herramienta democratizante para la implementación de los futuros cambios administrativos (Jácobi, 2002). Freire se oponía a las políticas verticalistas de los gobiernos tradicionales que lo precedieron. Se mostraba favorable a la delegación en la toma de decisiones y entendía que el poder era una construcción basado en la participación, la descentralización, la autogestión y la autonomía ${ }^{10}$. Por ello, cuando el Partido de los Trabajadores, a través de Paulo Freire, asumió en el área educativa de São Paulo se buscó favorecer estas concepciones.

Las medidas tomadas por el nuevo gobierno municipal se afirmaron en la aplicación de múltiples resoluciones. El Decreto n. ${ }^{\circ} 27813$ del 12 de junio de 1989 modificó la Superintendencia Municipal de Educación (Supeme) y el Departamento de Planea-

9 "Mais do que um conceito científico, trata-se de um conceito político-estratégico. proposta dos Conselhos de Escola para verificar em que medida parte das dificuldades enfrentadas por estes colegiados - os Conselhos de Escola- são características exclusivas de sua pratica na gestão escolar no período de 1989-1992" (Gadotti, 2003, p. 67)

10 Las medidas administrativas fueron analizadas por Torres et al. (1998). miento y Orientación (Deplan) en Coordinadora de los Núcleos de Acción Educativa (Conae). También cambiaron las Delegaciones regionales de educación municipal (DREM), que pasaron a llamarse Núcleos de acción educativa (NAE), dependientes directamente del Conae. Estas renovaciones no fueron superficiales, sino que tuvieron como objetivo alterar el sentido de la toma de decisiones en la gestión pública educativa. De esta manera, se promovió la participación a través de la implementación de órganos colegiados, basados en la toma de decisiones a nivel local, intermedio y también central.

En este marco de reformas, los consejos de escuela ${ }^{11}$ fueron organizados con la finalidad de implementar políticas públicas con fuertes vínculos y articulaciones con el movimiento social y con el conjunto de las comunidades de base. Se buscaba que las escuelas se constituyeran en organizaciones sociales orientadas según las necesidades y acuerdos entre quienes participaran en ellas, fueran estudiantes, profesores, personal no docente o vecinos del mismo barrio. El rol de los funcionarios debía ser el de acompañar este proceso, garantizando el nuevo entramado de relaciones y decisiones populares. La autogestión, en definitiva, el autogobierno, inspiraba estas iniciativas particulares desde la política pública:

La escuela demostrará madurez ejerciendo su capacidad de autogobernarse. Devolveremos las programaciones curriculares y otros materiales arbitrariamente retirados al inicio de la administración anterior, por ser patrimonio de las escuelas. Desencadenaremos un proceso de discusión para la construcción de nuevas propuestas curriculares. La escuela precisa ser un espacio vivo y democrático donde todas las preguntas sean llevadas seriamente, privilegiando la acción educativa en un saludable pluralismo de ideas. (SME-SP, 1989; énfasis del original)

Los consejos de escuela tenían una representación colegiada y estaban integrados por el director de las escuelas y representantes de los docentes, personal administrativo, padres y alumnos. Por lo general estaban constituidos por unos 20 a 40 miembros, garantizando su proporcionalidad según la población total de cada escuela. El porcentaje de representantes de padres y alumnos debía ser igual a los representantes del equipo escolar. La duración de los cargos era de un año y tenían la opción de que cualquiera de sus

11 Para algunos investigadores brasileros, un antecedente de los consejos de escuela en el pensamiento freiriano lo constituyen los llamados "círculos de padres e professores" impulsados desde los años sesenta en Recife. Véase Canhoto de Lima (2007). 
miembros podía ser elegido como presidente, siempre que tuviera más de 18 años. La excepción a esta última reglamentación la constituían las escuelas de adultos: en ellas el presidente del consejo podía ser también un estudiante. Las reuniones del Consejo estaban organizadas y planificadas en el calendario escolar y se establecía un encuentro por mes. Las temáticas abordadas eran muy amplias, aunque siempre centrada en temáticas educativas, incluso aquellos ítems relacionados con la organización de los recursos financieros de cada escuela. Generalmente se le proporcionaba a los colegiados la capacidad de tomar decisiones y asumirse como responsables de sus acciones ante la comunidad, tal como lo describen los Documentos oficiales de la Secretaría de Educación de São Paulo ${ }^{12}$.

Los consejos fueron propuestas que se articulaban con otras experiencias preexistentes en São Paulo. Muchas de ellas tenían sus raíces en las acciones llevadas a cabo por las organizaciones sociales y su lucha por reivindicaciones educativas. Un ejemplo de ello lo constituyó el denominado "Movimiento de lucha por las guarderías", creado en 1973 en la zona sur del estado de São Paulo, a partir del impulso dado por los "clubes de madres" (Gohn, 1992, p.78); otro caso significativo lo constituyó el Movimiento de Alfabetización de Jóvenes y Adultos (MOVA) ${ }^{13}$.

Sin embargo, esta experiencia de consejos no fue sencilla de llevar a cabo; la participación y compromiso de la comunidad llevó su tiempo, y a partir de entrevistas realizadas a quienes fueron parte de estas iniciativas se puede deducir que no resultó suficiente con crear la ingeniería estatal participativa para garantizar su apropiación por parte de la comunidad. El mismo Freire resaltaba como obstáculo la tradición burocrática en buena parte de la administración escolar estatal:

Considerando nuestras tradiciones autoritarias, era de esperar que, en algunos casos, la autoridad hipertrofiada de algunas directoras de escuelas intentase asfixiar el consejo en su nacimiento. En otros casos, al contrario, el consejo podría intentar la exacerbación de su poder y procurar obstruir a la directora. (Freire, 1997, p. 48)

En este sentido también se manifestaban los docentes que participaron en aquella experiencia:

La directora se mostraba contraria a la idea de la formación del Consejo Escolar, no solo omitiendo la divulgación de las informaciones de reuniones sino

12 Documentos SME-SP, 1992, p. 93.

13 Sobre este tema, véase Boschi (1988). también posesionándose en contra de su constitución [...] ella creía que se formaba un poder paralelo integrado por personas que no entendían nada de educación. (Antunes, 2005, p. 56)

Lógicamente un proceso de semejante magnitud no tuvo una respuesta positiva automática, máxime cuando el proceso movilizador en la ciudad, y en gran parte del Brasil, iba en un sentido contrario al planteado por muchas de las reformas. Esto se dio especialmente en el campo educativo en el que los procesos movilizadores más inmediatos en torno a la escuela estatal tenían antecedentes y experiencias circunscriptas a los intereses sectoriales, es decir, reivindicaciones docentes, estudiantiles o no docentes. Al menos en el espacio urbano, la participación en el marco de la escuela estatal tuvo ese carácter.

\section{Reorganización curricular y participación popular}

Diferente era la dinámica de los movimientos sociales y su relación con la educación en términos más amplios, tal como ocurrió a la hora de organizar desde la Secretaría Municipal de Educación bajo la gestión de Freire el Movimiento de Alfabetización para Jóvenes y Adultos. Allí, desde un comienzo, era la comunidad organizada la que impulsaba estas iniciativas en clave de educación popular, y fue ella quien cogestionó y garantizó con el Municipio la continuidad y la actualización de estas experiencias. De esta manera, el Estado, y, por ende, la política pública, debían estar al servicio de la construcción de poder popular, y la escuela, además de "formar sujetos sociales", debía constituirse - afirmaban desde la gestión - en "un instrumento de lucha de las clases populares" (SME, 1989, p. 89).

Una clara expresión de este proceso fue el crecimiento constante de los consejos escolares en el Municipio de São Paulo durante todo este periodo. En 1992 la red municipal de enseñanza estaba formada por 684 consejos de escuela y 10 consejos regionales desempeñándose conforme a la normativa establecida por la Dirección de Escuelas Municipales de la ciudad. Este proceso se extendió prontamente a otros estados - Paraná y Rio Grande do Sul, especialmente-con experiencias similares.

En los años subsiguientes a las reformas de la gestión de Freire se generó en el campo educativo de São Paulo una fuerte tendencia democratizadora. La manera de interpretarla, en este caso desde el punto de vista de la educación popular, trajo un fuerte debate que tuvo como centro la escuela pública. Se trataba de "reinventar", como le gustaba decir a 
Freire, la concepción de escuela pública estatal considerándola como un ámbito acorde a las demandas y necesidades populares.

Para el campo democrático popular, cuando se habla de descentralización, participación, ciudadanía y autonomía en el universo educacional, se está hablando de crear condiciones para ampliar la esfera pública del estado, ya que en el capitalismo, lo estatal termina siendo privado. (Gadotti, 2003, p. 89)

Otra de las reformas destacadas en esta etapa fue el Movimiento de Orientación Curricular (Freire, 1997). Uno de sus principios centrales fue impulsar una etapa de problematización de la situación curricular en las escuelas, para analizar y debatir en cada institución los rasgos y las marcas que definían sus propuestas curriculares. El conjunto de estas reformas y su implementación contó con el apoyo de profesores de la Universidade Estadual de Campinas (Unicamp), Universidade Estadual de Sao Paulo (UNESP) y Pontificia Universidade de Sao Paulo (PUC-SP), entre otras instituciones superiores del estado de São Paulo.

Para llevar adelante esta reforma, la Secretaría de Educación comenzó a elaborar y distribuir documentos en los que esbozaba lo que entendía que debían ser los lineamientos generales para debatir en cada escuela entre los estudiantes, profesores, no docentes y funcionarios. Se recuperaba un concepto que caracterizó no solo a las propuestas freirianas sino también al Partido de los Trabajadores durante estos años. La idea se basaba en un diseño curricular participativo, tal como se enunciaba en los documentos de la Secretaría con los que se "pretendía abrir el debate y estimular la reflexión y la discusión sobre el currículum, instrumento organizador de la escuela anhelada" (SME-SP, 1989).

En el documento de debate curricular se esbozaba con claridad cuál debía ser la función social de la educación, y en particular de la escuela pública; además, se destacaba su rol emancipador y promotor de la formación social crítica en la que el pueblo sea su real protagonista:

La actual administración se compromete a la construcción de una escuela pública popular que tenga como marca principal la educación como práctica de la libertad [...] Una escuela para la formación social y crítica, en busca de una sociedad democrática [...] que se caracterice como una escuela seria, en la apropiación, la recreación de conocimientos y, al mismo tiempo, estimuladora de la solidaridad y de la curiosidad [...] [Una escuela] en la que el pueblo participe de la adquisición y crítica de un saber que tenga en cuenta sus necesidades y sea instrumento de la emancipación. (SM-SP, 1989)
De allí que en tiempos de la gestión freiriana de São Paulo, aparte de la reforma curricular y del diseño de los Mova para jóvenes y adultos, se establecieran circuitos formativos para aquellos educadores populares que no habían obtenido sus diplomas docentes o para quienes realizaban tareas de voluntariado. Esta cuestión naturalmente era seguida de cerca por los gremios docentes que reclamaban la calificación de los educadores en cuestión. En este tema Freire acompañó sus demandas y coordinó con los movimientos sociales y con muchos de los educadores populares la creación de circuitos formativos que les otorgaban una mayor capacitación para llevar adelante esa tarea.

Así, desde la Secretaría de Educación, se creó en 1990 el Centro de Formación Permanente de Educadores, que tenía la finalidad de garantizar el proceso de formación continua para los docentes de las escuelas primarias y medias. El documento presentado por Ana M. Saul, responsable de una de las direcciones de la gestión municipal, proponía crear: "Un espacio totalmente dedicado a la formación permanente de los educadores de la Red Municipal de Enseñanza de San Pablo, básicamente, salas-ambiente, infraestructura de apoyo logístico y coordinación, funcionamiento del predio ocupado por la Guardia Civil Metropolitana" (SME-SP, 1990).

De conjunto, la reorganización curricular contemplaba diferentes aristas, además de la formación docente. Los núcleos centrales en los que se sustentó fueron, entonces, la construcción colectiva, que debía expresarse a través de un amplio proceso participativo en las decisiones y acciones sobre el currículo.

De esta manera, el terreno educativo no estuvo exento de este proceso de transformación social; la asociación de conceptos tales como escuelas públicas populares, educación liberadora, organizaciones sociales, cambio social y gestión significó el intento de construir un nuevo modelo de participación popular en la vida. Se llevaron a cabo propuestas basadas en la autonomía de los movimientos sociales y especialmente en tomar sus experiencias de construcción como base para las articulaciones de las nuevas políticas públicas ${ }^{14}$.

En este marco de transformaciones, las reformas freirianas de esta etapa fueron presentadas como iniciativas de articulación entre la gestión pública, los movimientos sociales y las comunidades de base. De

14 Otra de las propuestas de reforma más radicales llevadas a cabo por la gestión de Freire fue la elección de los directores de escuela por parte de la comunidad a través del voto directo. En marzo de 1991 presentó esta iniciativa para la discusión pública, pero la misma fue rechazada por los profesores y directivos de las escuelas municipales. Véase Elisalde, 2020, p. 109. 
tal modo, la educación popular modificó y redefinió su estrategia de construcción y aplicación, fundamentalmente al trasladar sus propuestas dentro de las fronteras del Estado, a fin de organizar, reclamar y luchar por políticas que resuelvan las necesidades de los(as) trabajadores(as), respeten la autonomía de las organizaciones y propongan la construcción de una educación en clave emancipadora, solidaria e impulsora de la organización popular.

La elaboración de un modelo de escuela pública y popular fue planteada por la nueva gestión como un proceso de activa relación participante entre sus integrantes, así como de apropiación creativa por la propia sociedad, con la intención de transformarla, como decía Freire, en "un espacio de organización política de las clases populares" y de "formación de sujetos políticos y sociales".

\section{El legado de la educación freiriana: la construcción de escuelas públicas populares ${ }^{15}$}

En los años 80, con las consecuencias del terrorismo de Estado -en particular las dictaduras militares del Cono Sur- y la emergencia posterior de las democracias neoliberales, la educación popular se constituyó nuevamente en buena parte de Latinoamérica en símbolo de la resistencia frente a las reformas educativas conservadoras que cubrían el continente ${ }^{16}$. Con el protagonismo de los movimientos sociales (Movimiento de los Sin Tierra en Brasil ${ }^{17}$, las empresas recuperadas en la Argentina, o las organizaciones campesinas en México, Colombia y Bolivia, entre otras) se instaló la iniciativa de crear escuelas/bachilleratos/universidades populares e interculturales autogestionadas, según los intereses y la tradición histórica de los

15 Este apartado ("El legado de la educación...) y el siguiente, “Teoría y praxis...", está basado en el trabajo Elisalde (2020), Cap. v.

16 Es fundamental destacar la activa resistencia del sindicalismo docente frente a los procesos de reforma neoliberal.

17 Véase Dal Ri (2008). trabajadores, además de reclamar al Estado que asumiera la responsabilidad de garantizar el funcionamiento democrático del sistema educativo ${ }^{18}$.

De esta forma, "Tomar la educación en nuestras manos" fue la consigna escogida por las organizaciones sociales para dar cuenta del protagonismo de un inédito e informal movimiento político pedagógico que tenía como meta construir otra escuela pública posible, luego de que la tormenta neoliberal trajera exclusión y miseria en buena parte de Latinoamérica. Desde estas posiciones se asumió la educación popular como bandera, incorporando a sus reivindicaciones históricas el derecho a la acreditación de sus iniciativas educativas, ya que bajo los nuevos tiempos la población excluida llegaba a millones. Así, la creación de escuelas se presentó como una nueva estrategia de la educación popular para concluir con la exclusión educativa y a la vez aportar nuevas formas para la organización de las clases populares en clave de sujetos políticos.

Este ascendente proceso planteó, y continúa haciéndolo, intensos debates respecto de la aplicación de sus estrategias de construcción en el campo educativo, así como un interesante desafío respecto de la perdurabilidad de sus construcciones y de su espíritu emancipador. Muchas de estas iniciativas en Latinoamérica han logrado "arrancarle"19 al burocratismo estatal reivindicaciones, tales como la gestión de sus propias escuelas populares, la creación de espacios formativos e incluso la obtención de recursos para sostener estas iniciativas.

Desde estas situaciones, surgieron nuevas problemáticas y desafíos como consecuencia de la etapa que el movimiento social debía enfrentar; cómo organi-

18 Un testimonio sobre los movimientos sociales en Latinoamérica y sus experiencias educativas puede encontrarse en el documental La educación en movimiento: https://www.youtube.com/watch?v=FNsIi3lazhg. En este material se recorren selectivamente experiencias y protagonistas de la educación popular, así como se analizan las relaciones entre los movimientos sociales latinoamericanos con el Estado en la última década. Se destacan en esta presentación el Movimiento Sin Tierra de Brasil, la Universidad Indígena Boliviana, los Bachilleratos Populares en organizaciones sociales y el Consejo Regional Indígena del Cauca (CRIC) de Colombia, entre otros.

19 Esta expresión es común escucharla entre los militantes de movimientos sociales como el Movimiento Sin Tierra de Brasil, las empresas recuperadas y los Bachilleratos populares de la Argentina. Denota la naturaleza de la incidencia de la acción y la lucha de las organizaciones al obtener sus reivindicaciones. 
zar las escuelas, cómo dar cuenta y continuidad de los logros obtenidos, de qué manera garantizar la durabilidad de los recursos y, sobre todo, cómo darle continuidad al temple militante y emancipador que dio origen a este proceso, eran algunos de los interrogantes a contemplar. Este panorama va a crear la necesidad de nuevas reflexiones y relaciones entre praxis y teoría, entre las cuales van a sobresalir, por su complejidad histórica, las relaciones de la educación popular con el Estado y las estrategias de las organizaciones populares ${ }^{20}$.

\section{Teoría y praxis pedagógica en la educación popular}

La historia de los movimientos populares en Latinoamérica demuestra que su desarrollo está vinculado con las consecuencias sociales del propio sistema capitalista, y sus formas de reproducción de la fuerza laboral. Las condiciones de vida de las grandes ciudades se caracterizan por profundas dificultades en la satisfacción de las necesidades básicas como salud, vivienda, trabajo y educación; y es especialmente en estos aspectos en los que se identifican las mayores carencias de las clases populares. Esta realidad demuestra la ascendente dificultad del sistema capitalista de asegurar la producción, distribución y organización de los medios de consumo fundamentales para la vida cotidiana de las personas. Estos problemas no pueden ser entendidos como deficiencias del sistema económico, sino principalmente como una característica particular de la "lógica incorregible del sistema", en el marco del desarrollo social, según afirma Mészáros (2008). La educación fue parte del proceso generalizado de precarización que afectó a toda Latinoamérica, expresado en fuertes desigualdades, comprobables a través del crecimiento de la exclusión y en el aumento del analfabetismo, además de otros indicadores de signo negativo para este ámbito.

Fue por estas causas que desde los años 80 y 90 los movimientos sociales dieron cuenta de esta situación, e iniciaron el reclamo por la necesidad de escuelas, becas y aportes integrales para los estudiantes, así como políticas que atiendan a la educación de jóvenes y adultos, probablemente la modalidad más postergada del sistema educativo.

En algunos países de la región este proceso fue asumiendo una especial perspectiva, caracterizándose por una novedosa relación del movimiento

20 Sobre educación popular, saberes y movimientos sociales, véase Pérez Wilke et al. (2020). social con la educación, sobre todo en lo referido a sus influencias teórico-culturales y en sus decisiones prácticas. Esta línea se planteó desde múltiples tradiciones, pero es indudable que la más influyente fue la representada por el pensamiento de Paulo Freire, así como también por otros autores clásicos pertenecientes al campo de la educación social, según nos destacó una de las coordinadoras entrevistadas, perteneciente al Movimiento Sin Tierra del Brasil ${ }^{21}$.

Este conjunto de relaciones entre educación popular, compromiso social y trabajo nos invita a considerar una primera conceptualización; esto es, la educación de los movimientos sociales como praxis pedagógica, porque de esto trata esta cosmovisión.

Se entiende la praxis pedagógica ${ }^{22}$ desde una doble relación conceptual: por un lado, en el "hacer político" y, por el otro, en las "prácticas formativas". "Hacer" y "(auto)formarse" son nociones que acompañan la lógica vinculante con la dimensión educativa de los movimientos sociales (Gadotti, 2003). Este vínculo fue expresado por numerosas organizaciones latinoamericanos a través del ascendente protagonismo asumido en el campo educativo durante la etapa reformista neoliberal.

Las políticas aplicadas por el Banco Mundial y por instituciones tecnocráticas multinacionales impulsaron un proceso de "reforma por arriba" con un contundente impacto en los sistemas educativos latinoamericanos (Elisalde y Acri, 2017). Los efectos de "expulsión" de las escuelas de grandes masas de jóvenes y adultos ${ }^{23}$ y la degradación educativa fue acompañada por una precarización laboral y académica, con la oposición, en ese entonces, de maestros y profesores, especialmente en el terreno gremial a través de activas denuncias y movilizaciones de los sindicatos alertando a la comunidad sobre los efectos devastadores que traería el reformismo de esos años.

Este proceso encontró también en la resistencia de los movimientos sociales un rol ciertamente activo. Fueron estas organizaciones las que, en algunos casos, se lanzaron a presionar, reclamando más y mejor edu-

21 Nos estamos refiriendo a las ideas de la emblemática obra freiriana y a clásicos rusos como Wesley Pistrak y Anton Makarenko, entre otros. En Entrevista a Cristina: Coordinadora de educación del MST-Brasil. 2011.

22 La contratara dialéctica de la praxis pedagógica es la propia idea pedagógica: no existe la una sin la otra. La idea pedagógica se sustancia en la praxis. Véase Saviani (2007).

23 Freire prefería llamar "expulsados" a los estudiantes que quedaban fuera de las escuelas y señalaba que existía un vínculo directo entre deserción escolar y clases populares. 
cación, y, en otros, apelando a novedosas estrategias autogestionarias que dieran cuenta de la educación que el Estado les había negado (o precarizado).

En los movimientos sociales latinoamericanos se evidenció el novedoso legado de Paulo Freire, proveniente de sus años en la gestión: asumir las escuelas públicas "como organizaciones sociales de las clases populares"; e incluso con una "recreación" aún más desafiante desde el nuevo milenio: crear escuelas desde y por los movimientos sociales, con derechos a la acreditación a los estudiantes que cursan en "sus escuelas populares o incluso en sus universidades interculturales". La provocación de este planteamiento genera tensión con algunas tradiciones propias de la educación popular que sustentan que estas experiencias no debían adentrarse en los sistemas educativos porque correrían el riesgo de ser "cooptadas por los Estados" o que "las verdaderas representaciones de la educación popular deben ser entendidas por fuera de los sistemas educativos públicos"24. Tal como fue presentado, estos desafíos y renovados conceptos que estrechaban vínculos entre "escuela y educación pública-popular" fueron desarrollados oportunamente por el propio Freire durante su gestión educativa, no solo al proponer la articulación con las iniciativas ya existentes en los territorios de las organizaciones sociales, sino también por redefinir y renovar conceptualmente el campo de la propia educación ${ }^{25}$. La creación de escuelas/universidades públicas populares a lo largo y a lo ancho de Latinoamérica es un proceso que aún no ha terminado y expresa a las experiencias de educación popular más dinámicas y novedosas de la región ${ }^{26}$.

La formación de sujetos políticos manifestó, de esta manera, el imprescindible complemento entre praxis pedagógica y emancipación social. La escuela

24 Estos debates aún no han concluido, y según las referencias teóricas o experienciales, se reafirma una u otra legitimación de origen para la educación popular. Véase el dosier sobre educación popular en la Revista Polifonías (n. ㄱ, año IV, 2015); también el excelente trabajo de Alfonso Torres (2016).

25 Cabe mencionar que el vínculo entre organizaciones de trabajadores (as) impulsando y creando escuelas populares remite también a históricas tradiciones en las que el movimiento obrero disputaba con el capital, e incluso con el Estado, en la creación de escuelas y universidades populares. Sobre estos temas puede consultarse: Elisalde et ál. (2013).

26 Estas problematizaciones no significan negar la impresionante existencia en todo nuestro continente de los cientos de miles experiencias de educación popular desarrolladas por fuera de los sistemas educativos, sino de relevar e interpretar los emergentes sociales del nuevo milenio que vinculan estrechamente la educación popular con la escuela, en un vínculo ciertamente diferenciado a las décadas precedentes. enseña, pero debe realizar algo más que enseñar y aprender, "debe prepararnos para la acción, la solidaridad de clase y la rebelión", decía Freire desde sus documentos de la Secretaría de Educación (SMSP, 1990).

Crear escuelas si el estado no las provee, ocuparlas si no da cuenta de una perspectiva emancipadora y exigirles que los recursos públicos se plasmen en la apertura de nuevas escuelas en aquellas regiones que no las tienen, o que no satisfacen las demandas de la comunidad, de esos se trata la práctica de nuestros movimientos. (DossIER MST, 2005)

Las organizaciones sociales definieron llevar adelante acciones que tenían como objetivo reclamar y crear escuelas, y argumentaban que era necesario contar con más educación para sus comunidades. Las clases populares percibían con nitidez los procesos de precarización y de permanente retiro del estado del campo educativo. En estas circunstancias, la necesidad precedió a la decisión política de numerosos movimientos sociales decididos a dar cuenta en la acción directa de las deficiencias ocasionadas por el reformismo neoliberal.

Estas acciones no tuvieron un carácter meramente subsidiario de las políticas educativas negadas por el Estado, sino, por el contrario, manifestaron una praxis política consciente (Gramsci, 1981), en el sentido de interpelar la hegemonía cultural en el escenario de uno los subsistemas centrales del capitalismo.

Rápidamente, la resistencia de los movimientos sociales se tradujo en acciones que buscaron suplir parte de los déficits de la política pública, pero también es necesario destacar que a medida que este proceso fue desenvolviéndose en una praxis consciente, la definición de objetivos se amplió y radicalizó, argumentando la necesidad de "construir poder popular", según manifestaban las propias organizaciones sociales. Esto implicó desarrollar una construcción basada en una memoria histórica consciente, con un importante protagonismo de los (as) trabajadores (as) y sus representaciones en el terreno educativo, expresadas en históricas pujas con el capital.

Estas situaciones provocaron que numerosas comunidades asuman las temáticas educativas desde sus movimientos - sin abandonar en muchos casos el posicionamiento acerca de que el Estado debía continuar siendo el garante del sistema público de educación, por ejemplo, en recursos y acreditación-, pero aceptando y reconociendo el protagonismo autogestionario de las organizaciones a la hora de crear escuelas y universidades, conforme a las necesidades de sus localidades. 
En numerosas experiencias en la región, los movimientos sociales llevan adelante estas acciones con el apoyo y la articulación de equipos de docentes e investigadores de educación popular vinculados a las universidades públicas ${ }^{27}$.

En definitiva, este proceso implicó pasar de la reivindicación del derecho a la educación a la formulación de qué escuela no es la que se desea y finalmente a la construcción de una escuela diferente, como afirmaba Paulo Freire en sus escritos. Así, la creación de escuelas/universidades públicas populares a lo largo y a lo ancho de Latinoamérica es un proceso que no solo no ha terminado, sino que continúa en toda la región (Rodrigues Brandao, 2017) ${ }^{28}$. A la vez, nos invita provocativamente a debatir sobre los múltiples caminos de renovación de la educación popular en la actualidad, basados en experiencias impulsadas por los movimientos sociales y anticipadas conceptualmente en los años de la gestión de Paulo Freire al frente a la Secretaría de Educación de São Paulo, durante el periodo1989-1991.

\section{Conclusiones}

En síntesis, en esta presentación se analizó y problematizó uno de los aspectos menos tratados en la vida y producción de Paulo Freire: "el desafío de construir educación popular en el marco de la política pública" (SME-SP, 1989) y su legado actual en las experiencias educativas de numerosos movimientos sociales de Latinoamérica.

La abundante documentación publicada por la Secretaría Municipal de Educación, además de los numerosos debates recuperados en la prensa de la época, nos permitió reconstruir no solo el carácter de las iniciativas pedagógicas, sino también los aspectos conflictivos para su implementación. Es indudable que si bien el horizonte político sobre el que se fijaron los cambios llevados a cabo en la gestión educativa se sustentaba en que el Partido de los Trabajadores se consolidara como una real organización de los(as) trabajadores(as) y que garantizase la creación de poder popular, lo cual no implicó que dicho proceso fuera desarrollado sobre la base de un amplio consenso en el sector educacional. Todo lo contrario. Existieron en la gestión profundas tensiones entre los sectores moderados del Partido de los Trabajadores y el gobierno municipal, encabezado por la

27 Entrevista a docente escuela del Movimiento Sin Tierra, julio de 2011.

28 Este trabajo nos propone un notable recorrido teórico y experiencial de la educación popular desde sus años fundacionales. prefecta Luiza Erundina (del ala más radicalizada del Partido) y principal apoyo de Freire en la Secretaría de Educación. Conflictos con la burocracia escolar intermedia y superior (inspectores, directores, personal administrativo), conflictos con los gremios docentes (reclamos sectoriales de base estatutaria) y una población (padres y estudiantes) acostumbrada a percibir la política estatal en clave de directivas o, en muchos casos, a través de normativas autoritarias fueron algunos de los condicionantes existentes con los que Freire y su equipo se encontraron a la hora de intentar llevar a cabo un "proceso emancipador" en la escuela y la educación paulista.

La reforma administrativa, la renovación pedagógica "por abajo" y especialmente los consejos de escuela se constituyeron en la avanzada principal de los cambios que aspiraban a lograr una democracia radical y una pedagogía participativa en las escuelas. La experiencia se implementó a pesar de las resistencias y se convirtió en un indudable legado para la educación popular latinoamericana. Por su parte, iniciativas como el Movimiento de Reorganización Curricular y la Formación Docente Permanente fueron desarrollados e incorporados como contraparte cognitiva - en clave de nuevos y comprometidos contenidos- de una reforma educativa más amplia, basada en contenidos "liberadores".

Pero, sin duda, el conjunto de propuestas y legado freiriano durante sus años de gestión no podría comprenderse en toda su dimensión e influencia futura sin su vínculo, articulación y reapropiación por parte de los movimientos sociales. La educación popular y las escuelas, a diferencia de los años 60 y 70, parecen confluir y rediseñar las nuevas formas que asume la organización popular en el terreno educativo desde el segundo milenio. Las miles de escuelas populares y universidades interculturales en y desde los movimientos sociales latinoamericanos así parecen demostrarlo.

En los últimos años se evidencia un proceso diferenciado y notable en la región en los que el vínculo escuelas públicas-educación popular se destaca, tal como se argumentó en este artículo, bajo la "recreación de escuelas" y el protagonismo de organizaciones sociales y novedosos sindicatos docentes, llamados por algunos protagonistas como "sindicatos territoriales" 29 . En ellos, se suman las luchas reivindicativas

29 Esta expresión "sindicatos territoriales" fue mencionada en el Panel Educación Pública-Popular, Sindicatos Docentes y Organizaciones Sociales, integrado por organizaciones sindicales latinoamericanas, en el Ix Seminario Internacional organizado por la Red de Investigadores y Organizaciones Sociales de América Latina (Riosal-Clacso) y el viI Congreso Pedagógico del SuTEF de Tierra del Fuego, durante noviembre del 2020. 
laborales junto a prácticas y acciones de construcción de poder popular en y desde sus escuelas. Podemos detectar estas experiencias de sur a norte de nuestro continente; en México, con el Sindicato Nacional de Trabajadores de la Educación en Lucha (SNTE); en Colombia, con el gremio magisterial de la Asociación de Institutores y Trabajadores de la Educación del Cauca (Asoinca) y en la Argentina con el Sindicato de Trabajadores de Educación de Tierra del Fuego (SUTEF) y el Movimiento Pedagógico de Liberación (MPL-Misiones). Finalmente, desde las organizaciones territoriales, sin duda, debemos destacar al histórico Movimiento Sin Tierra de Brasil y su extendida y prolífica creación de escuelas territoriales, o los centenares de bachilleratos populares de jóvenes y adultos existentes en empresas recuperadas por tanto sus trabajadores como por organizaciones sociales de la Argentina, desde los primeros años del nuevo milenio.

\section{Referencias}

Antunes, A. (org.) (2005). Conselhos de escola. Inst. Paulo Freire.

Boschi, R. (1988). Movimentos coletivos no Brasil urbano. Zahar.

Canhoto de Lima, M. R (2007). Paulo Freire e a administração escolar. Líber Libro Editora.

Dal Ri, N. (2008). Educação democrática e trabalho associado no Movimento dos trabalhadores sem terra e nas empresas de autogestão. Ícone Ed. 2008

Documentos de la Secretaría Municipal de Educação de São Paulo (SME-SP). (1989-1991).

Diário Folha de S. Paulo, 1988-1991.

Elisalde, R. (2020). Educación popular, Estado y movimientos sociales. Una experiencia de gestión al frente de la Secretaría de educación de San Pablo (1989-1991). Biblos.

Elisalde, R., Acri, M. y Duarte, D. (comps.). (2013). Historia de la Educación Popular. Experiencias hegemónicas y contrahegemónicas en Latinoamérica (18701940). Facultad de Filosofia y Letras, Universidad de Buenos Aires. http://publicaciones.filo.uba.ar/ historia-de-la-educaci\%C3\%B3n-popular

Elisalde, R. y R, Acri, M. (2017). Historia de la Educación Popular. Experiencias hegemónicas y contrahegemónicas en Latinoamérica (1940-2019). FFYL-UBA: http:// publicaciones.filo.uba.ar/historia-de-la-educaci\%C3\%B3n-popular-en-latinoam\%C3\%A9rica
Fernandes, F. (1983, 17 de agosto). Foro de Educación del estado de San Pablo, San Pablo, Brasil.

Freire, P. (1997). La educación en la ciudad. Siglo XXI.

Freire, P. (1998). Pedagogia de la Autonomia. Siglo XxI.

Gadotti, M. (2003). Pedagogía de la praxis. Aparicio.

Gadotti, M. (2008). Mova Brasil. Inst. Paulo Freire.

Gramsci, A. (1981). Notas sobre Maquiavelo. Nueva Visión.

Gohn, M. da G. (1992). Teoría dos movimentos sociais. Ed. Loyola.

Jacobi, P. (2002). Políticas sociais e ampliação da cidadania. FGV.

Keck, M. (1991). A lógica da diferencia o Partido dos TrabaIhadores na construção da democracia. Ática.

Lima, L. (2002). Organização democratização escolar e democracia radical. Paulo Freie e a governarão democrática da escola publica. Cortez editora.

Mészáros, I. (2003). O século XXI. Socialismo o barbárie? Boitempo Editorial.

Mészáros, I. (2008). La educación más allá del capital. Siglo XXI.

Pérez Wilke, I., Ampudia, M., Torres, A. y Cabezas, D. (2020). La producción popular del saber. Claves Latinoamericanas. Editorial Riosal-Chilevert.

Rodrigues Brandao, C. (2017). La educación popular de ayer $y$ de hoy. Biblos.

Saviani, D. (2007). História das idéias pedagógicas no Brasil. Autores Associados.

Sposito, M. (1984). O povo vai ir a escola: a luta popular pela expansão do ensina público, Loyola.

Torres, A. (2016). Educación popular y movimientos sociales em América Latina. Biblos.

Torres, J. C., O'Caliz, M. y Wong, P. (1998). Educação e democracia. Praxis de Paulo Freire en S. Paulo. Westview Press. 

